\title{
Relationship between Leadership Styles of School Principals and Whistleblowing Behaviors of Teachers ${ }^{{ }^{*}}$
}

\author{
Abbas Erturk*, Emrah Donmez ${ }^{* *}$ \\ Faculty of Education, Mugla Sitki Kocman University, Turkey \\ Corresponding Author: abbasertu@gmail.com*,emrahdonmez123@gmail.com**
}

Copyright $\bigcirc 2016$ by authors, all rights reserved. Authors agree that this article remains permanently open access under the terms of the Creative Commons Attribution License 4.0 International License

\begin{abstract}
This study aims to determine the relationship between leadership styles of school principals and whistle blowing behaviors of teachers. The sample of this study, which is designed in the relational survey model, consists of 393 teachers working in primary, secondary and high schools in the province of Mugla. The data were collected through "School Principal Leadership Style Scale" and "Whistleblowing Scale". In data analysis, descriptive statistics and regression analysis were applied. According to the findings obtained from these data, it was identified that teachers preferred internal whistleblowing at the highest level whereas they opted for external whistleblowing behavior at the lowest level. Besides, according to teachers' opinions, it was asserted that at the very most level school principals demonstrated transformational leadership behaviors. In addition, it was also determined that there was a medium level of significant relationship between the leadership styles school principals demonstrated and whistle blowing behaviors of teachers. Moreover, it was stated that as long as school principals demonstrated transformational leadership behaviors, teachers mostly preferred the internal whistleblowing type of behavior. On the other hand, it was remarked that teachers opted for anonymous whistleblowing behaviors as long as school principals demonstrated laissez-faire leadership behaviors.
\end{abstract}

Keywords Whistleblowing, Leadership Styles, Teacher

\section{Introduction}

Professional life has been changing and developing rapidly. Depending on these change and development, administration and supervision processes have also improved. These developments ensure that some negative points, observed by employees working in organizations, have aroused and eliminated. We have been encountering with a quite different concept every passing day due to the researches related to these negative behaviors and elimination of them. One of these concepts is whistleblowing. Whistleblowing is a concept attached to leaking information about the negative matters taking place in the organizations. In order words, leaking information regarding an ethical or an illegal event was denominated with the concept of "whistleblowing". These negations might sometimes be either simple mistakes or great malfeasances; and occasionally an individual's telling this information to somebody else might rescue the organization from serious damages [11]. According to Near and Miceli [20], whistleblowing refers to that an employee of the organization reveals an unethical or illegal application about his organization. Besides, according to Erturk [10], whistleblowing behavior is a phenomenon which has emerged due to the fact that there is no transparency. In the organization in which transparency does not take part, violations and whistleblowing behavior, which is applied so as to serve for organizational purposes and in order for these violations to emerge, have developed as a requirement or a last resort.

Whistleblowing (standing for whistling with the intent of drawing attention to a mistake) was first given place in some of the documents of USA senate in the year of 1963 [13]. When the concept of whistleblowing was first developed, it was perceived as the employees giving a bad name to his organization and that's why it was exposed to rather serious criticisms. Afterwards, the application of whistleblowing behavior began to be encouraged as soon as the benefits of this behavior were realized. The concept was interpreted into Turkish as "grassing the ethical problems", "employees' revealing the intra-organizational malfeasances or illegal activities", "civic virtue, moral reaction or conscientious refusal towards the unethical wrong applications in the organizations" "whistleblowing" and "disclosure of information" [19].

According to Aktan [21], whistleblowing behavior is usually perceived as "espionage". However, according to Erturk [10], the definitions developed about this concept make away with this wrong perception. In many definitions regarding this behavior, it has been emphasized that 
whistleblowing serves organizational purposes. In order for an event to be regarded as whistleblowing, the whistleblower is required to perform this behavior by paying attention to public interest instead of his individual interests. It is also identified in most of the definitions that whistleblowing is a type of behavior which is demonstrated based on good faith; paying regard to public interest and performed with the purpose of preventing the damages other individuals might meet with [21] and [20].

According to Erturk [10], the violations taking place in the organizations in which there are not any transparencies and whistleblowing behaviors might be concealed. Concealing the violations in the organizations can be regarded as an acceptable and permissible behavior by some employees. This behavior is generally construed with organizational commitment. However such behaviors might damage the organization, employees working in the organization and individuals getting service from the organization. From this point of view, behaviors which are demonstrated by employees and also which are regarded as the only source in order to prevent these damages and violations are quite important.

In the studies conducted about whistleblowing, this behavior has been investigated in four different sub-dimensions. These dimensions are internal whistleblowing, external whistleblowing, supportive whistleblowing and anonymous whistleblowing [6]. Internal whistleblowing refers to that an employee transmits a negative event taking place in an organization to a superior authority in the same organization. An employee's transmitting the situation to an internal authority stands for the fact that he considers that internal authorities might be effective in dealing with the violations in the organization and therefore the problem can be resolved by the internal dynamics of the organization. However, unless the authority who is internally whistleblown interferes in these violations, then the whistleblower might apply to external authorities [9]. External whistleblowing means an employee's transmitting the violations he has encountered in the organization to the competent units from the outside of the organization. The setting in which this whistleblowing behavior will take place might be such institutions as media organizations, institutions apart from the organization or police departments as well [19]. In addition, supportive whistleblowing is a whistleblowing behavior occurring when an individual shares the violations in the organization primarily with his colleagues and the whistleblower expects support from these colleagues so as to whistle blow [6]. On the other hand, anonymous whistleblowing is a type of whistleblowing which an individual performs without giving his own personal information. If an individual considers that the information he transmits might be a threat risk either by other employees or by the organization, he can prefer whistleblowing anonymously [15].

Whistleblowing has been discussed in scientific studies regarding various fields in many countries. The studies conducted in Turkey demonstrate obviously that many employees prefer keeping silent against the negations taking place in the organizations [22]. According to the study of Toker Gokce [23], it was identified that among 164 teachers, 32 of them stated that they had witnessed any illegal action whereas 11 of them (34\%) remarked that they has whistleblown. In another study conducted by Toker Gokce [24], it was determined that $46 \%$ of teachers who had encountered any negative event demonstrated whistleblowing behavior. In addition, according to the study of Erturk [10], it was concluded that there was a low level of positive and significant relationship between the levels of teachers' whistleblowing behaviors and their organizational behaviors. That's to say, teachers whose levels of organizational citizenship were high, performed whistleblowing behavior at a high level as well. This situation can be regarded as an indicator of that whistleblowing might be a behavior which is performed by putting the organizational interests into account. According to the study conducted by Celep and Konakli [6], it was confirmed that among the reasons of teachers' whistleblowing behaviors, first of all teachers' taking into consideration the interests of their school and other individuals in the school is involved.

In this study, it has been assumed that the type of teachers' whistleblowing behaviors might show differences according to the leadership styles demonstrated by their school principals. At schools, the individuals who are expected to be leaders are primarily the school principals. In this context, the leadership behaviors that school principals demonstrate might have an influence on teachers' behaviors not only in a supportive way but also in a negative way [18]. The types of leadership, namely transformational leadership, laissez-faire leadership and transactional leadership have been dealt in this study. The reason why these leadership types are selected is that they take part among new approaches in leadership [12]. Transformational leadership is regarded as a leadership style which can maintain the necessary transformation in order to comply with the rapidly changing environment [2]. Transformational leadership is a leadership style in which the leader gives more importance to the objectives and missions of the group more than his own objectives and missions [17]. In this leadership style, creating confidence and esteem in the organization comes into prominence [7]. The leaders adopting transformational leadership style are individuals who have characteristics such as communicating perpetually, being open to innovations and being people oriented [8]. Transformational leadership style can be utilized in many periods since it is a leadership style which is open to new innovations [16]. Besides, laissez-faire leadership is a leadership style in which leaders behave in an uninterested way; they abstain from giving decisions and they cannot be reached when needed [2]. In this leadership style, an active leader cannot be mentioned because the leader is in an indifferent manner and he is not interested in the problems of the group. Besides, such leaders are in the position of releasing their employees completely in performing their duties. When there appears to 
be a problem, the leader expects his employees to deal with and resolve the problem instead of interfering in the problem. Moreover, it is rather difficult to make decisions in this leadership style and delays might be experienced when some decisions are needed to be made [16]. Transactional leadership stands for a leadership style which aims to increase the effectiveness and productiveness, both of which are regarded as the extensions of behavioristic ecole [4]. Transactional leadership evaluates the relationships between the leader and group as a kind of exchange process [17]. Additionally, this leadership style relies on the perfomance of indiviual taking part in the group beacuse the leader is rewarded according to his performance. Also, this leadership style is based on the assumption that the group has got fundamentally limited information, opinion and resolving power. In accordance with this, within the scope of transactional leadership, members of the group are endevaoured to be motivated externally, financialy and by using rewards such as changing the woking conditions [26]. The entity of leader is attached to leader's evaluating and rewarding the employees. However, this leadership style cannot be applied in each and every field. In order for this leadership to be utilized, working conditions, objectives and structures are required to be clear and alterations in the working environment should be quite a few [2].

As mentioned above, whistleblowing has various types and it has been identified in many studies that whistleblowing is applied in different ways by teachers working in schools. The leadership styles which school principals demonstrate can be determinant in teachers' selecting their different whistleblowing methods. In order words, it can be considered that the leadership styles school principals apply might have an influence on the preferences of teachers about the different whistleblowing methods. In this regard, the purpose of this study is to determine the relationship between leadership styles of school principals and whistleblowing behaviors of teachers. In order to reach this purpose, the questions below were tried to be answered throughout the study:

1. What is the level of teachers' whistleblowing?

2. What are the opinions of teachers regarding the leadership styles of school principals?

3. Do the leadership styles demonstrated by school principals predict the whistleblowing behaviors of teachers?

\section{Method}

\subsection{Research Model}

Being a quantitative research, this study was designed in the relational survey model.

\subsection{Population and Sample}

The population of this study consisted of 12.053 teachers working in primary, secondary and high schools in the province of Mugla during 2015-2016 academic year. The sample of this study was selected by using disproportionate cluster sampling. Besides, the sample size was calculated as 372 teachers for $95 \%$ confidence level. Supposing that there might be data loss, 400 teachers were determined to apply the data collection instruments. Analyses were conducted on 393 attained data collection instruments, which were practicable, among 400 forms collected from teachers. 56\% of the participants were female whereas $44 \%$ of them were male; $51 \%$ of teachers were at the ages of $31-45$; besides $33 \%$ of the participants were working at primary schools, $26 \%$ of them at secondary schools, $19 \%$ of them at general high schools and lastly $22 \%$ of them at vocational high schools.

\subsection{Data Collection Instruments}

The data collection instrument comprised of three parts. In the very first part, demographic characteristics of teachers were given place. Additionally, in the second part Whistleblowing Scale was utilized. This scale was developed by Celep and Konakli [6]. The scale consisted of four dimensions and totally 16 items. These dimensions are internal whistleblowing ( 5 items, variation $26.38 \%$ ), external whistleblowing (4 items, variation 22.08\%), supportive whistleblowing (4 items, variation $13.76 \%$ ), and anonymous whistleblowing (3 items, variation 9.28\%). The total variation explained by all the dimensions of the scale together was $71.5 \%$. Besides, the Cronbach Alpha internal consistency coefficient for the total scale was calculated as $\alpha=0.76$. In the analysis performed for this present study, it was identified that the total variation explained regarding the scale was $62.9 \%$ and the Cronbach Alpha internal consistency coefficient for the total scale was found to be $\alpha=0.82$. In the last part of the data collection instrument, School Principal Leadership Style Scale was included. This aforementioned scale was developed by Akan, Yildirim and Yalcin [1]. The scale consisted of three dimensions and 35 items. These dimensions were called as transformational leadership (20 items, variation 37.4\%), transactional leadership ( 7 items, variation $4.3 \%$ ), and laissez-faire leadership ( 8 items, variation $12.45 \%$ ). In addition, the total variation explained by the dimensions of scale was found to be $54.19 \%$. Moreover, for the total scale, the Cronbach Alpha internal consistency coefficient was calculated as $\alpha=0.82$. According to the analyses of this present study, it was identified that the total variation explained related to the scale was $62.9 \%$ and the Cronbach Alpha internal consistency coefficient for the total scale was calculated as $\alpha=0.82$. Both of the scales could be answered in the intervals from " $1=$ totally disagree" and " $5=$ totally agree". The scores obtained from the scales were evaluated as (1.00-1.80) "none", (1.81-2.60) "low", (2.61- 3.40) "medium", (3.41-4.20) "high" and (4.21-5.00) "very high", respectively. 


\subsection{Data Analysis}

Within the scope of this study, in order to determine teachers' opinions, descriptive statistics, t-test and one-way analysis of variance (Anova) were applied. For significant $F$ values, so as to identify the source of this significance, Tukey test, one of the multiple comparison tests was utilized. In the analysis regarding the prediction of variables, regression analysis was applied. The correlation coefficient was described as low for the values between 0.00-0.29, medium between the values of 0.30-0.69 and high between the values of $0.70-1.00[5]$.

\section{Findings}

In Table 1, the distribution of teachers' whistleblowing behaviors regarding its dimensions was presented.

Table 1. The distribution of teachers' whistleblowing regarding its dimensions

\begin{tabular}{|c|c|c|c|c|}
\hline Scale & Dimensions & $\mathrm{n}$ & $\bar{X}$ & $\mathrm{~S}$ \\
\hline \multirow{5}{*}{ Whistleblowing } & Internal Whistleblowing & 383 & 3.94 & .76 \\
\hline & External Whistleblowing & 355 & 2.22 & .94 \\
\hline & $\begin{array}{l}\text { Supportive } \\
\text { Whistleblowing }\end{array}$ & 370 & 3.17 & 1.08 \\
\hline & $\begin{array}{l}\text { Anonymous } \\
\text { Whistleblowing }\end{array}$ & 386 & 2.61 & 1.06 \\
\hline & Total Whistleblowing & 330 & 3.06 & .63 \\
\hline
\end{tabular}

When Table 1 is investigated, it can be identified that teachers preferred internal whistleblowing at the highest level $(\overline{\mathrm{X}}=3.94, \mathrm{~S}=.76)$ whereas they opted for external whistleblowing at the lowest level $(\overline{\mathrm{X}}=2.22, \mathrm{~S}=.94)$. It can also be inferred from the table that the total whistleblowing level of teachers was found to be at the medium level $(\overline{\mathrm{X}}=3.06, \mathrm{~S}=.63)$. Moreover, the distribution of teachers' opinions related to the leadership styles of their school principals was given in Table 2 .
Table 2. School principals' leadership styles according to teachers' opinions

\begin{tabular}{ccccc}
\hline Scale & Dimensions & $\mathrm{n}$ & $\overline{\mathrm{X}}$ & $\mathrm{S}$ \\
\hline $\begin{array}{c}\text { School } \\
\text { Principals } \\
\text { Leadership Styles }\end{array}$ & $\begin{array}{c}\text { Transformational } \\
\text { Leadership }\end{array}$ & 349 & 3.80 & .84 \\
\cline { 2 - 5 } & Laissez-Faire Leadership & 369 & 2.29 & .86 \\
\cline { 2 - 5 } & $\begin{array}{c}\text { Transactional } \\
\text { Leadership }\end{array}$ & 364 & 2.80 & .70 \\
\hline
\end{tabular}

According to Table 2, it can be stated that according to teachers' perceptions, school principals demonstrated transformational leadership style at the very most $(\overline{\mathrm{X}}=3.80$, $\mathrm{S}=.84)$ while they performed laissez-faire leadership $(\overline{\mathrm{X}}=2.29, \mathrm{~S}=.86)$ at the least proportion. Besides, it can be also be asserted that school principals demonstrated transactional leadership style at a quite low level $(\overline{\mathrm{X}}=2.80$, $\mathrm{S}=.70$ ), as well. In addition, the results of the regression analysis, which was performed so as to determine whether or not the leadership styles, school principals demonstrated, predicted teachers' internal whistleblowing behaviors were included in Table 3.

When Table 3 is examined, it can be stated that there was a positive, significant and medium level of relationship between the total leadership styles demonstrated by school principals and the internal whistleblowing behaviors of teachers $(\mathrm{R}=0.317, \mathrm{p}<0.05)$. Besides, as a whole, the leadership styles demonstrated by school principals explained $10 \%$ of the total variation related to teachers' internal whistleblowing behaviors. According to the standardized regression coefficient $(\beta)$, the order of the comparative importance regarding the leadership styles demonstrated by school principals was respectively as follows: transformational leadership, laissez-faire leadership and transactional leadership. When t-test results about the significance of regression coefficients are investigated, it can be remarked that only the transformational leadership styles of school principals were determined to be the significant predictors of teachers' internal whistleblowing behaviors. However, other leadership styles of school principals were not found to be significantly effective. According to the results obtained from this study, regression equation for teachers' internal whistleblowing behaviors was given below:

Internal Whistleblowing $=2.568+0.314$ Transformational Leadership +0.031 Laissez-Faire Leadership +0.27 Transactional Leadership

Table 3. Regression analysis results regarding the prediction of internal whistleblowing behaviors

\begin{tabular}{ccccccccc}
\hline Variable & $\mathrm{B}$ & Standard Error & $\beta$ & $\mathrm{T}$ & $\mathrm{p}$ & Binary $\mathrm{r}$ & Partial $\mathrm{r}$ \\
\hline Constant & 2.568 & .355 & & 7.241 & .000 & & \\
\hline Transformational Leadership & .314 & .063 & .345 & 4.995 & .000 & .314 & .274 \\
\hline Laissez-Faire Leadership & .031 & .082 & .034 & .375 & .708 & -.161 & .021 \\
\hline Transactional Leadership & .027 & .084 & .025 & .323 & .747 & -.085 & .018 \\
\hline & & $\mathrm{R}=0.317^{*}$ & $\mathrm{R}^{2}=0.101$ & $\mathrm{~F}_{(3,308)}=11.477$ & $\mathrm{p}=0.000$ & &
\end{tabular}


Moreover, in order to determine whether or not the leadership styles of school principals predicted the external whistleblowing behaviors of teachers, regression analysis was applied and the related results were presented in Table 4 .

When Table 4 is investigated, it can be obviously remarked that the relationship between the total leadership styles demonstrated by school principals and the external whistleblowing behaviors of teachers was determined to be positive, significant and at a low level $(\mathrm{R}=0.217, \mathrm{p}<0.05)$. In addition to this, the leadership styles of school principals, all together explained $5 \%$ of the total variation related to teachers' external whistleblowing behaviors. According to the standardized regression coefficient $(\beta)$, in terms of external whistleblowing behaviors, the importance order of the leadership styles demonstrated by school principals was found to be respectively as the following: laissez-faire leadership, transactional leadership, and transformational leadership. Besides, according to the t-test results about the significance of regression coefficients, it can be asserted that not only the laissez-faire leadership styles but also transactional leadership styles of school principals were identified as the significant predictors of teachers' external whistleblowing behaviors. Yet, transformational leadership styles of school principals were not determined to be significantly effective on teachers' external whistleblowing behaviors. In accordance with the results obtained from this study, the regression equation for teachers' external whistleblowing behaviors was given below: External Whistleblowing $=1.852+0.049$ Transformational Leadership + 0.365 Laissez-Faire Leadership - 0.221

Transactional Leadership
On the other hand, regression analysis results attained in order to determine whether the leadership styles of school principals predicted teachers' supportive whistleblowing behaviors are represented in Table 5 .

According to Table 5, it can be indicated that there was a positive, and low level of relationship, which is not significant, between the total leadership styles demonstrated by school principals and the supportive whistleblowing behaviors of teachers $(\mathrm{R}=0.128, \mathrm{p}>0.05)$. On the one hand, school principals' leadership styles all together explained just $2 \%$ of the total variation regarding teachers' supportive whistleblowing behaviors. On the other hand, according to the standardized regression coefficient $(\beta)$, in terms of supportive whistleblowing behaviors of teachers, the relative importance order for the leadership styles demonstrated by school principals was respectively as follows: laissez-faire leadership, transformational leadership, and transactional leadership. When t-test results about the significance of regression coefficients are investigated, it can be asserted that the leadership styles of school principals were determined to have no significant effects on teachers' supportive whistleblowing behaviors. Furthermore, according to the results obtained from this study, regression equation for teachers' supportive whistleblowing behaviors was presented below:

Supportive Whistleblowing $=2.294+0.107$

Transformational Leadership + 0.201 Laissez-Faire

Leadership + 0.006 Transactional Leadership

Table 4. Regression analysis results regarding the prediction of external whistleblowing behaviors

\begin{tabular}{cccccccc}
\hline Variable & $\mathrm{B}$ & Standard Error & $\beta$ & $\mathrm{T}$ & $\mathrm{p}$ & Binary $\mathrm{r}$ & Partial $\mathrm{r}$ \\
\hline Constant & 1.852 & .479 & & 3.865 & .000 & & \\
\hline Transformational Leadership & .049 & .083 & .045 & .584 & .560 & -.101 & .034 \\
\hline Laissez-Faire Leadership & .365 & .108 & .323 & 3.366 & .001 & .178 & .193 \\
\hline Transactional Leadership & -.221 & .103 & -.168 & -2.135 & .034 & .035 & -.124 \\
\hline \multicolumn{2}{c}{$\mathrm{R}=0.217^{*}, \quad \mathrm{R}^{2}=0.05}$, & $\mathrm{F}_{(3-292)}=4.821$, & $\mathrm{p}=0.003$ & & & \\
\hline
\end{tabular}

${ }^{*} \mathrm{p}<0.05$

Table 5. Regression analysis results regarding the prediction of supportive whistleblowing behaviors

\begin{tabular}{cccccccc}
\hline Variable & $\mathrm{B}$ & $\begin{array}{c}\text { Standard } \\
\text { Error }\end{array}$ & $\beta$ & $\mathrm{T}$ & $\mathrm{p}$ & Binary $\mathrm{r}$ & Partial $\mathrm{r}$ \\
\hline Constant & 2.294 & .527 & & 4.351 & .000 & \\
\hline Transformational Leadership & .107 & .093 & .085 & 1.147 & .252 & -.019 & .066 \\
\hline Laissez-Faire Leadership & .201 & .119 & .161 & 1.684 & .093 & .109 & .096 \\
\hline Transactional Leadership & .006 & .119 & .004 & .052 & .958 & .083 & .003 \\
\hline & $\mathrm{R}=.128^{*}$ & $\mathrm{R}^{2}=0.02$ & $\mathrm{~F}_{(3-302)}=1.673$ & $\mathrm{p}=0.173$ & & \\
\hline
\end{tabular}

$* \mathrm{p}<0.05$ 
Table 6. Regression analysis results regarding the prediction of anonymous whistleblowing behaviors

\begin{tabular}{ccccccccc}
\hline Variable & $\mathrm{B}$ & $\begin{array}{c}\text { Standard } \\
\text { Error }\end{array}$ & $\beta$ & $\mathrm{T}$ & $\mathrm{p}$ & Binary $\mathrm{r}$ & Partial $\mathrm{r}$ \\
\hline Constant & 1.016 & .484 & & 2.098 & .037 & & \\
\hline Transformational Leadership & .174 & .086 & .141 & 2.028 & .043 & -.082 & .114 \\
\hline Laissez-Faire Leadership & .454 & .111 & .375 & 4.103 & .000 & .268 & .226 \\
\hline Transactional Leadership & -.039 & .113 & -.027 & -.345 & .731 & .185 & -.020 \\
\hline & $\mathrm{R}=.292^{*}$ & $\mathrm{R}^{2}=0.084$ & $\mathrm{~F}_{(3-312)}=9.527$ & $\mathrm{p}=0.000$ & & & \\
\hline
\end{tabular}

$* \mathrm{p}<0.05$

Additionally, in Table 6, the results of the regression analysis which was concluded in order to determine whether or not the leadership styles of school principals predicted anonymous whistleblowing behaviors of teachers were presented.

According to Table 6, it can asserted that there was determined to be a positive, significant and low level of relationship between the total leadership styles demonstrated by school principals and the anonymous whistleblowing behaviors of teachers $(\mathrm{R}=0.292, \mathrm{p}<0.05)$. Besides, the leadership styles of school principals, all together was found to explain $8 \%$ of the total variation about teachers' anonymous whistleblowing behaviors. Moreover, according to the standardized regression coefficient $(\beta)$, in terms of anonymous whistleblowing behaviors of teachers, the importance order of the leadership styles demonstrated by school principals was found to be respectively as the following: laissez-faire leadership, transformational leadership and transactional leadership. When the t-test results regarding the significance of regression coefficients are investigated, it can be stated that the dimensions of both transformational leadership and laissez-faire leadership styles of school principals could be regarded as significant predictors of anonymous whistleblowing behaviors of teachers. However, school principals' transactional leadership styles were identified to be insignificantly effective on teachers' anonymous whistleblowing behaviors. In the light of the results obtained from this study, for the anonymous whistleblowing behaviors of teachers the regression equation was given below:

Anonymous Whistleblowing $=1.016+0.174$

Transformational Leadership +0.454 Laissez-Faire

Leadership - 0.039 Transactional Leadership

\section{Results, Conclusions and Recommendations}

In this study, it was aimed to determine the relationship between leadership styles of school principals and whistle blowing behaviors of teachers. In this context, the relationships between the dimensions of school principals' leadership styles, namely transformational, laissez-faire and transactional leadership and the four dimensions of whistleblowing called as internal, external, supportive and anonymous whistleblowing behaviors were investigated through this study. According to the results of this study, the level of teachers' whistleblowing was determined to be low, in general. The results of the studies conducted before in literature support this result of the study. In the study of Toker Gokce [24], it was concluded that $34 \%$ of teachers having encountered with any violations demonstrated whistleblowing behavior.

When the dimensions of whistleblowing are arranged in an order from the highest arithmetic means to the lowest means, the order takes shape as follows: internal, supportive, anonymous and external whistleblowing. The preference level of teachers for internal whistleblowing was determined to be higher when compared to other whistleblowing types. The study of Toker Gokce [24], which was conducted on teachers, corresponds to this result of the study. Besides, in another study conducted by Celep and Konakli [6] whose participants were primary and secondary school teachers, a similar result was obtained. Moreover, it was also concluded in the study of Okdem and Shahbazi [14] regarding the attitudes of Turkish society, it was concluded that Turkish people mostly prefered internal whistleblowing. The fact that internal whsitleblowing is prefered by teachers can be regarded as a positive matter for the educational organizaiton. Because internal whistleblowing stands for the sensiblity of teachers, who are the most important part of educational institutions, related to the violations taking place in the instutions they work. Additionaly, when the process is managed in an accurate way, internal whistleblowing enables that the problems taking part in the organizations are resolved by the internal dynamics of the organization as soon as possible. In spite of this, teachers' preferance level of external whisleblowing behavior was determined to be lower than all the other whistleblowing types. In this regard, it can be asserted that teachers have confidence in the internal processes of their organizations in order to deal with any negative events taking place in their organizations. That the external whistleblowing takes place in the last row when the whistleblowing types are put in an order indicates that external whistleblowing is the least prefered type of whistleblowing by teachers. Therefore, it denotes that teachers do not put external dynmacis into account in resolving the problems occuring in their organizations, even it represents that teachers consider those external dynamics as the last resort when there seem to be problems. It can be also be stated that this situation might result from the organzational sensibility of teachers. As well as these 
aforementioned points, this situation also indicates that teachers puts a great deal of importance in not damaging the organization while they are trying to resolve the intra-organziational problems. According to the study of Celep and Konakli [6], teachers mostly whistleblow as a result of organizational interest, moral and professional values. Moreover, according to MacNab, Brislin, Worthley et al. [25], on the condition of internal whistleblowing, an organization can have a change to correct the mistakes on its own right without letting the organization to get more damaged.

On the one hand, internal whistleblowing of teachers has a positive, significant and medium level of relationship with the transformational leadership styles of school principals whereas there is a negative, significant and low level of relationship between teachers' anonymous whistleblowing and school principals' transformational leadership styles. In other words, as long as school principals' transformational leadership behaviors increase, teachers tend to whistle blow internally while they abstain from anonymous whistleblowing (Figure 1).

On the other hand, there is found a positive, significant and low level of relationship between the dimension of anonymous whistleblowing behaviors of teachers and the laissez-faire leadership styles of school principals, while this aforementioned dimension has a negative, significant and low level of relationship with school principals' transformational leadership styles. This situation indicates that as the laissez-faire leadership behaviors demonstrated by school principals increase, teachers' anonymous whistleblowing behaviors also increase (Figure 1). When the leadership styles are taken into consideration, this can be regarded as an expected condition because transformational leadership helps to increase the level of confidence between leader and employees and to enhance the relationship between them [8]. Thus, the need for whistleblowing anonymously regarding the violations which take place in the organization and which are observed by employees disappears. Besides, laissez-faire leadership can be described as the absence of leadership in a sense [3]. Thereby, the element of confidence cannot be mentioned in the relationship of employee-leader. That's why employees working in the organization need to whistleblow anonymously about the violations which take place in the organization and which are observed by employees. By this way, the employee takes care of that his own information is kept confidential so that he can keep himself in a trustworhty position.

When investigated in terms of the dimensions of leadership styles, transformational leadership has a positive relationship with internal whistleblowing whereas it has negative realtionships with all the other dimensions, namely supportive, anonymous and external whistleblowing. Besides, laissez-faire leadership and transactional leadership styles demonstrated by school principals have positive relationships with only the dimension of internal whistleblowing while they have negative relationships with the other dimensions. That's to say, in terms of whistleblowing behaviors, transformational leadership styles of school principals have a reverse effect when compared to other leadership styles which are transactional leadership and laissez-faire leadership styles. This situation supports how important transformational leadership behaviors are from the viewpoint of revealing wholesomely the violations in an organization.

In literature, there have been many studies conducted about leadership. Thereby, it is possible that the concept of leadership is comprehended by school principals and teachers; they consider about the benefits of leadership and reflect many positive attitudes about leadership into their own behaviors. This study brings a new different dimension related to the benefits of leadership for teachers and school principals. This dimension is called as whistleblowing which is a concept connected to finding out the intra-organizational negations. Even though whistleblowing is generelly perceived as a negative or distant expression in a society, this study might be supposed to contribute in introdoucing the concept of whistleblowing in an accurate way. When considered from this point of view, it can be quite useful to introduce the concept of whistleblowing to the school principals and teachers and also to clarify the relationship between whistleblowing and leadership.

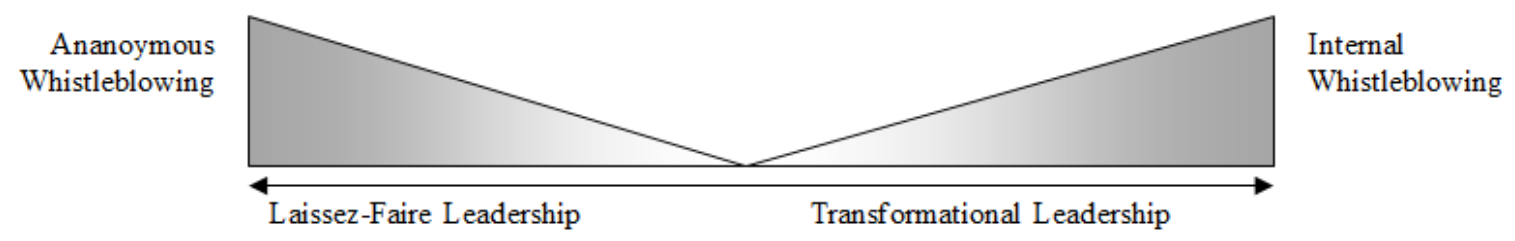

Figure 1. Relationship between Leadership and Whistleblowing 


\section{Note}

*The abstract of this paper was presented at 2nd International Conference on Lifelong Learning and Leadership for All (ICLEL-16), in Liepaja on July, 21-23, 2016.

\section{REFERENCES}

[1] Akan, D., Yildirim, İ. \& Yalcin, S. (2014). Developing a school principle as leadership style scale. Electronic Journal of Social Sciences, 13(51), 392- 415. Retrived April 30, 2016 from www.esosder.org.

[2] Aslan, S. (2013). Gecmisten gunumuze liderlik kuramlari (Saglik yonetimi bakis acisiyla). Konya: Egitim Kitapevi.

[3] Aydin, A. \& Sarier, Y. (2013). Investigation of the relationship between the leadership of educational administrators and school outcomes, using the method of meta-analysis. Abant Izzet Baysal University Journal of Faculty of Education, 12(2), 258-275.

[4] Bolat, T., A. Seymen, O., İ. Bolat, O. \& Erdem, B. (2016). Yonetim ve organizasyon. Ankara: Detay Yayincilik.

[5] Buyukozturk, S. (2015). Sosyal bilimler icin veri analizi el kitabi: İstatistik, arastirma deseni, spss uygulamalari ve yorum (21. b.). Ankara: Pegem Akademi.

[6] Celep, C. \& Konakli, T. (2012). Whistleblowing: A response to unethical and illegitimate practices in educational organizations. E-International Journal Of Educational Research, 3(4), 65-88. Retrived April 22, 2016 from http://www.e-ijer.com.

[7] Cemaloglu, N. \& Kilinc, A. C. (2012). Okul the relationship between school administrators' leadership styles and teachers' organizational trust level. Mehmet Akif Ersoy University Journal of Faculty of Education, 132-156. Retrived 20, 2016 from http://dergipark.ulakbim.gov.tr

[8] Dogan, S. (2016). Cagdas liderlik yaklasimlari. N. Guclu, \& S. Kosar icinde, Egitim Yonetiminde Liderlik (s. 69-96). Ankara: Pegem Akademi.

[9] Eren, V. \& Orhan, U. (2013). An ampirical study about effect of the corporate social responsibility on level of employer's whistleblowing. The Journal of Academic Social Science Studies, 6(2), 455-468.

[10] Erturk, A. (2016). The relationship between whistleblowing and organizational citizenship behavior for high school teachers. Journal of Educational Sciences Research (JESR), 6(1), 1-22. doi:http://dx.doi.org/10.12973/jesr.2016.61.1

[11] Esen, E. \& Kaplan, H. A. (2012). Whistleblowing in organizations. Dokuz Eylul Universitesi Sosyal Bilimler Enstitusu Dergisi, 14(2), 33-52. Retrived April 22, 2016 from http://www.sbe.deu.edu.tr.

[12] Guclu, N. (2016). Liderlige genel bir bakis. N. Guclu, \& S. Kosar icinde, Egitim yonetiminde liderlik (s. 1-16). Ankara:
Pegem Akademi.

[13] Hersh, M. (2002). Whistleblowers-heroes or traitors? Individual and collective responsibility for ethical behaviour. Annual Reviews in Control, 26(2). doi: 10.1016/S1367-5788(02)00025-1., 243-262.

[14] Okdem, M. K., \& Shahbazi, G. (2012). Attitudes towards different forms of whistleblowing in Turkey and Iran. Middle-East Journal of Scientific Research, 7(12), 945-951. doi:10.5829/idosi.mejsr.2012.12.7.1778

[15] Park, H., Plenkinsopp, J., Oktem, M. K. \& Omurgonulsen, U. (2008). Cultural orientation and attitudes towards different forms of whistleblowing: A comparison of south Korea, Turkey, and the U.K. Journal of Business Ethics(82), 929-939. doi:10.1007/s10551-007-9603-1

[16] Sabuncuoglu, Z., \& Vergiliel Tuz, M. (2013). Orgutsel davranis. Bursa: Alfa Akademi Basim Yayim.

[17] Schermerhorn, J. R., Osborn, R. N. \& Uhl-Bien, M. (2007). Oraganizational behaviour (11. b.). United States of America: Wiley \& Sons, Inc.

[18] Serin, M. K. \& Buluc, B. (2012). The relationship between instructional leadership and organizational commitment in primary schools. Educational Administration: Theory and Practice, 18(3), 435-459. Retrived April, 222016 from www.ulakbim.gov.tr

[19] Zamantili Nayir, D. (2012). Kurumsal etik ve whistleblowing. İstanbul: Pozitif Yayinlari.

[20] Near, J.P. \& Miceli, M.P. (1985). Organizational dissidence: The case of whistleblowing. Journal of Business Ethics, 4(1), $1-16$.

[21] Aktan, C.C. (2006). Organizasyonlarda yanlis uygulamalara karsi bir sivil erdem, ahlaki tepki ve vicdani red davranisi: Whistleblowing. Mercek Dergisi, Ekim Sayisi, 1-13.

[22] Seckin, Z. \& Karasoy, H. A. (2012). A conceptual study on the relationship between the importance of whistle-blowing and organizational citizenship behavior. International Journal of Information Technology and Business Management, 6(1), 50-58.

[23] Toker Gokce, A. (2014). Whistle-blowing at Schools: The relationship between Job Satisfaction and Organizational Commitment. Dicle University Journal of Ziya Gokalp Faculty of Education, (22), 261-282.

[24] Toker Gokce, A. (2013). Relationship between whistle-blowing and job satisfaction and organizational loyalty at schools in Turkey. Educational Research and Reviews, 8(14), 1186-1197. doi: 10.5897/ERR2013.1485.

[25] MacNab, B., Brislin, R., Worthley, R., Galperin, B. L., Jenner, S., Lituchy, T. R., MacLean, J., Aguilera, G. M., Ravlin, E., Tiessen, J.H., Bess, D. \& Turcotte, M. F. (2007). Culture and ethics management whistle-blowing and internal reporting within a NAFTA country context. International Journal of Cross Cultural Management, 7(1), 5-28.

[26] Sahin, S. (2005). The Transformational and Transactional Leadership Styles of Primary School Principals (İzmir Case). Education and Science, 30(135), 39-49. Retrived April 23, 2016 from http://egitimvebilim.ted.org.tr.

\footnotetext{
${ }^{\mathrm{i}}$ This research was supported by Mugla Sttk1 Kocman University within the scientific research projects-16/120
} 